\title{
Osmotically-induced nerve taurine depletion and the compatible osmolyte hypothesis in experimental diabetic neuropathy in the rat
}

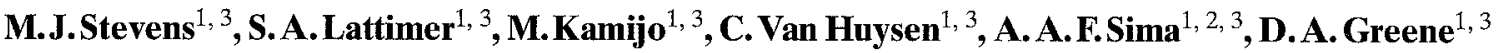 \\ ${ }^{1}$ Department of Internal Medicine, University of Michigan, Ann Arbor, Michigan, USA \\ ${ }^{2}$ Department of Pathology, University of Michigan, Ann Arbor, Michigan, USA \\ ${ }^{3}$ Diabetes Research and Training Center, University of Michigan, Ann Arbor, Michigan, USA
}

Summary. Diabetic neuropathy results from progressive nerve fibre damage with blunted nerve regeneration and repair and may be complicated by nerve hyperexcitability resulting in pain. The naturally occurring amino acid taurine functions as an osmolyte, inhibitory neurotransmitter, and modulator of pain perception. It is also known to have neurotrophic actions. The compatible osmolyte hypothesis proposes that levels of intracellular organic osmolytes including taurine and myo-inositol, respond co-ordinately in response to changes in intracellular sorbitol or external osmolality to maintain the intracellular milieu. We hypothesize that glucose-induced sorbitol accumulation in diabetes mellitus will result in taurine depletion in peripheral nerve which may potentially impair nerve regeneration and precipitate neuronal hyperexcitability and pain. This study explored the relationships of taurine, myo-inositol and sorbitol in the rat nerve and their effects on nerve conduction velocity. Osmolyte levels and nerve conduction velocity were determined in sciatic nerve from non-diabetic and streptozotocin-induced dia- betic rats, with or without dietary taurine or myo-inositol supplementation. Taurine levels decreased by $31 \%(p<$ $0.01)$ and myo-inositol decreased by $37 \%(p<0.05)$ in diabetic nerve as sorbitol accumulated. Taurine supplementation of diabetic animals did not affect nerve conduction velocity but further reduced nerve myo-inositol levels. Prevention of sorbitol accumulation with the aldose reductase inhibitor sorbinil increased nerve taurine levels by $22 \%$ $(p<0.05)$ when compared with untreated diabetic animals. Thus, we have demonstrated an interdependence of organic osmolytes within the nerve. Abnormal accumulation of one osmolyte results in reciprocal depletion of others. Diabetic neuropathy may be an example of maladaptive osmoregulation, nerve damage and instability being aggravated by taurine depletion.

Key words: Diabetes mellitus, experimental neuropathy, taurine, osmoregulation.
Although the cause of diabetic neuropathy remains unknown, evidence implicates involvement of the polyol pathway, by which glucose is metabolized to sorbitol and fructose by aldose reductase (AR2) and sorbitol dehydrogenase, respectively $[1,2]$. The compatible osmolyte hypothesis predicts that organic osmolytes including taurine, myo-inositol (MI) and sorbitol respond co-ordinately in response to changes in external osmolality to maintain the intracellular milieu [3]. Excess accumulation of intracellular sorbitol by activation of the polyol pathway in diabetes mellitus may therefore precipitate reciprocal depletion of other intracellular osmolytes. Depletion of nerve MI may result in disturbances of the calciumdependent phosphoinositide metabolism and secondary defects of nerve $\mathrm{Na} / \mathrm{K}$-ATPase activity, resulting in the acutely reversible slowing of nerve conduction $[2,4]$.

Taurine (2-aminoethanesulphonic acid) is an ubiquitous beta amino acid which has been shown to function as an osmolyte in the eye, brain and kidney [5-9]. Within the kidney, taurine has been identified as the major amino acid in the renal inner medulla of rats where it functions as an osmolyte with concentrations increasing in response to dehydration $[8,9]$. Taurine is widely distributed in man, being found in the highest concentrations in tissues which are prone to diabetic complications [10]. It functions as an anti-oxidant $[5,11]$ and inhibitory neurotransmitter $[12$, 13], and it promotes neuronal repair and regeneration [13]. It has analgesic properties as it acts as a modulator of central pain perception $[14,15]$. It regulates free cytosolic calcium and taurine deficiency results in increased free calcium and cell hyperexcitability $[16,17]$. The spontaneously diabetic BB-rat and the streptozotocin diabetic (STZ-D) rat demonstrate structural and functional neural lesions similar to those seen in diabetic patients [18]. Specifically, neuronal hyperexcitability [19], reduced nerve conduction velocity (NCV) and impaired nerve regene- 
ration occur early in the diabetic state $[18,20]$. We propose that taurine is essential for the maintenance of neuronal integrity, and hypothesize that taurine deficiency may result in nerve hyperexcitability responsible for early painful diabetic neuropathy.

The interrelationships of the osmolytes taurine, MI and sorbitol were studied in peripheral nerve of the STZ$\mathrm{D}$ rat after diabetes-induced nerve sorbitol accumulation or dietary supplementation of taurine or MI, or both. The functional effects of osmolyte disturbances were assessed by measuring sciatic nerve NCV.

\section{Materials and methods}

\section{Research design}

Cesarean-delivered, barrier-sustained, and overnight-fasted male albino Wistar rats weighing $200-300 \mathrm{~g}$, were used. They were rendered diabetic by an i. p. injection of streptozotocin $(60 \mathrm{mg} / \mathrm{kg})(\mathrm{Up}-$ john, Kalamazoo, Mich., USA) in $0.2 \mathrm{ml}$ of $10 \mathrm{mmol} / \mathrm{l}$ citrate buffer pH 5.5 [21]. Plasma glucose was determined from tail vein blood with a Beckman glucose analyzer II (Beckman Instruments, Fullerton, Calif., USA). For inclusion in the study, diabetic rats had to have a non-fasting plasma glucose concentration of greater than $16.7 \mathrm{mmol} / \mathrm{l}$ in heparinized tail vein blood, $48 \mathrm{~h}$ after STZ injection and at the end of the study. All animals were maintained in individual air-filtered metabolic cages and given access to water and suitably modified rat chow ad libitum. All synthetic diets were obtained from ICN Biomedicals (Cleveland, Ohio, USA).

Rats were acclimatized to their new environment for one week prior to the start of the study. All end-point measurements were made by investigators who were unaware of the identity of the experimental assignment. Two days after the induction of diabetes, animals were randomly assigned to the following experimental groups.

1. Non-diabetic control animals given standard synthetic rat chow (taurine undetectable, MI content $0.011 \%$ weight/weight (w/w));

2 . Non-diabetic animals given synthetic rat chow supplemented with $5 \% \mathrm{w} / \mathrm{w}$ taurine;

3. Diabetic animals given standard synthetic rat chow;

4. Diabetic animals given synthetic rat chow supplemented with $5 \%$ w/w taurine;

5. Diabetic animals given standard synthetic rat chow together with the ARI sorbinil suspended in distilled water (final concentration 4$5 \mathrm{mg} / \mathrm{ml}$ ) as previously described [2,21] and administered daily by gavage at a dose of $20 \mathrm{mg} / \mathrm{kg}$; and

6. Diabetic animals given synthetic rat chow supplemented with $1 \%$ w/w MI.

The duration of the experiment was 21 days after which the NCV was measured, and the left and right sciatic nerves were rapidly surgically exposed from the vertebral exit to the common peroneal bi- furcation, excised, and cleaned of adherent muscle and loose epineural connective tissue [22]. Nerve was immediately frozen in liquid nitrogen for subsequent determination of nerve osmolyte levels [23, 24]. Percutaneously $3 \mathrm{ml}$ of cardiac blood was withdrawn and centrifuged at $4^{\circ} \mathrm{C}$ for $15 \mathrm{~min}$ and $3300 \mathrm{rev} / \mathrm{min}$ to obtain plasma for determination of plasma osmolality.

\section{Measurement of NCV}

Animals were lightly anaesthetized with an injection of $30-40 \mathrm{mg}$ pentobarbitol sodium $/ \mathrm{kg}$ body weight i.p. and $\mathrm{NCV}$ was determined non-invasively in the left sciatic tibial conducting system [22]. The body temperature was monitored using a rectal probe and maintained at $37^{\circ} \mathrm{C}$ throughout the measurement using a warming pad. The left sciatic nerve was stimulated proximally at the sciatic notch and distally at the ankle via bipolar electrodes with supramaximal stimuli $(8 \mathrm{~V})$ from a stimulator at $20 \mathrm{~Hz}$. The latencies of the compound muscle action potentials were recorded via bipolar electrodes from the first interosseous muscle of the hindpaw. The latencies were measured from the stimulus artifact to the onset of the negative $\mathrm{M}$-wave deflection. The NCV was calculated by subtracting the distal latency from the proximal latency measured in milliseconds and the result was divided into the distance between the stimulating and recording electrodes measured in millimeters, giving a value for $\mathrm{NCV}$ in meters per second $(\mathrm{m} / \mathrm{s})$.

\section{Measurement of sciatic nerve MI, sorbitol and fructose}

Sciatic nerve MI, sorbitol and fructose were determined by gas chromatography of protein-free sciatic nerve homogenates $(5 \%$ weight/volume trichloroacetic acid), and expressed as nmol/mg wet weight of tissue using a modification of a method that we have previously described $[23,24]$. The determinations were performed on aldonitrile acetate derivatives of lyophilized aliquots of filtrates containing alpha-D-methyl mannopyranoside as an internal standard in a Varian 3700 gas-liquid chromatograph (Varian Sunnyvale, Calif., USA) with a single flame ionization detector. Samples were injected using a Varian 8100 autosampler and the data analysed on a Varian Star Workstation integrator. The instrument was equipped with one $30 \mathrm{~m}, 0.25 \mathrm{~mm}$ inner diameter SP-2100 fused silica capillary column with a $0.25 \mu \mathrm{m}$ film thickness. The column flow rate was $0.6 \mathrm{ml} / \mathrm{min}$ with a nitrogen carrier gas flow of $36.6 \mathrm{ml} / \mathrm{min}$ with a flame ionization detector maintained at $250^{\circ} \mathrm{C}$. Standard curves were generated daily.

\section{Measurement of taurine}

Sciatic nerve taurine concentrations were determined by high performance liquid chromatography (HPLC) using a modification of a method previously described [25] and expressed as nmol/mg wet weight. Approximately $20 \mathrm{mg}$ of nerve was homogenized in $1 \mathrm{ml}$ of $6 \%$ trichloroacetic acid (TCA) and then centrifuged for $15 \mathrm{~min}$ at $4000 \mathrm{rev} / \mathrm{min}$. To $0.5 \mathrm{ml}$ of supernatant, $0.5 \mathrm{ml}$ of TNO:freon [1:3]

Table 1. Comparison of body weight and plasma glucose in non-diabetic control, taurine supplemented non-diabetic control, diabetic, taurine supplemented diabetic, aldose reductase inhibitor (ARI) treated diabetic and myo-inositol (MI) supplemented diabetic rats at baseline and at the conclusion on day 21

\begin{tabular}{|c|c|c|c|c|c|c|}
\hline & $\begin{array}{l}\text { Control } \\
(n=10)\end{array}$ & $\begin{array}{l}\text { Control + taurine } \\
(n=8)\end{array}$ & $\begin{array}{l}\text { Diabetic } \\
(n=12)\end{array}$ & $\begin{array}{l}\text { Diabetic + taurine } \\
(n=8)\end{array}$ & $\begin{array}{l}\text { Diabetic + ARI } \\
(n=9)\end{array}$ & $\begin{array}{l}\text { Diabetic +MI } \\
(n=10)\end{array}$ \\
\hline Baseline weight $(\mathrm{g})$ & $268 \pm 14$ & $243 \pm 7$ & $254 \pm 7$ & $236 \pm 6$ & $254 \pm 6$ & $251 \pm 9$ \\
\hline Day 21 weight (g) & $377 \pm 19$ & $364 \pm 11$ & $271 \pm 14^{\mathrm{a}}$ & $277 \pm 13^{\mathrm{a}}$ & $278 \pm 11^{\mathrm{a}}$ & $287 \pm 11^{\mathrm{a}}$ \\
\hline Day 2 glucose $(\mathrm{mmol} / \mathrm{l})$ & $6.6 \pm 0.4$ & $7.6 \pm 0.2$ & $25.6 \pm 1.6^{\mathrm{a}}$ & $26.7 \pm 1.6^{\mathrm{a}}$ & $24.8 \pm 2.1^{\mathrm{a}}$ & $24.4 \pm 1.7^{a}$ \\
\hline Day 21 glucose $(\mathrm{mmol} / \mathrm{l})$ & $7.8 \pm 0.5$ & $7.8 \pm 0.5$ & $28.8 \pm 1.3^{\mathrm{a}}$ & $30.7 \pm 1.8^{\mathrm{a}}$ & $30.4 \pm 0.9^{\mathrm{a}}$ & $28.5 \pm 1.2^{\mathrm{a}}$ \\
\hline
\end{tabular}

${ }^{\mathrm{a}} p<0.01$ vs control and control + taurine. Data given as mean $\pm \mathrm{SEM}$ 
Table 2. Effect of diabetes and $5 \%$ dietary taurine supplementation ( + taurine) on nerve conduction velocity (NCV) in the left sciatic tibial conduction system after 21 days in non-diabetic control (control) animals and streptozotocin-induced diabetic (diabetic) animals. The effects of sorbinil $(20 \mathrm{mg} / \mathrm{kg})(\mathrm{D}+\mathrm{ARI})$ administration and $1 \%$ dietary myo-inositol (D + MI) supplementation in diabetic animals are also shown

\begin{tabular}{lllll}
\hline \multicolumn{3}{c}{ The effect of diabetes and taurine feeding } \\
& $\begin{array}{l}\text { Control } \\
(n=10)\end{array}$ & $\begin{array}{l}\mathrm{C}+\text { taurine } \\
(n=8)\end{array}$ & $\begin{array}{l}\text { Diabetic } \\
(n=12)\end{array}$ & $\begin{array}{l}\mathrm{D}+\text { taurine } \\
(n=8)\end{array}$ \\
\hline $\mathrm{NCV}(\mathrm{m} / \mathrm{s})$ & $55.11 \pm 0.9$ & $48.6 \pm 2.1$ & $42.2 \pm 1.6^{\mathrm{a}}$ & $45.0 \pm 3.3^{\mathrm{b}}$ \\
\hline \multicolumn{5}{c}{ The effect of sorbinil and myo-inositol feeding } \\
& $\begin{array}{l}\text { Diabetic } \\
(n=12)\end{array}$ & $\begin{array}{l}\mathrm{D}+\mathrm{ARI} \\
(n=9)\end{array}$ & $\begin{array}{l}\mathrm{D}+\mathrm{MI} \\
(n=10)\end{array}$ \\
\hline $\mathrm{NCV}(\mathrm{m} / \mathrm{s})$ & $42.2 \pm 1.6$ & $49.5 \pm 0.8^{\mathrm{c}}$ & $48.3 \pm 1.8^{\mathrm{c}}$ & \\
\hline
\end{tabular}

${ }^{\mathrm{a}} p<0.01,{ }^{\mathrm{b}} p<0.05$ vs control; ${ }^{\mathrm{c}} p<0.05$ vs diabetic. Data given as mean \pm SEM

(trioctylamine: 1,1,2-trichlorotrifluoroethane) was added and vortexed for $1 \mathrm{~min}$. After confirming that betaine was not present in the nerve samples and did not appear after exposure to the experimental conditions, betaine ( $500 \mathrm{nmol}$ in $10 \mu \mathrm{l}$ ) was used as internal standard. The sample was again centrifuged for $15 \mathrm{~min}$ at $4000 \mathrm{rev} / \mathrm{min}$. The aqueous supernatant was then passed through a $0.45 \mu \mathrm{m}$ filter to remove any significant particulate matter. All HPLC data were collected on a Waters system (Waters Chromatography Division, Millipore Corp., Milford, Mass., USA) equipped with a model 600 pump and a manual injector, a model 410 differential refractometer and a column heater module. Data was recorded and processed on a Waters 746 data module. A Sugar Pak 1 (Waters) calcium cation exchange column $(300 \times 6.5 \mathrm{~mm})$ was used as the stationary phase. The column was pre-heated and maintained at $87^{\circ} \mathrm{C}$. The mobile phase consisting of HPLC grade water with $50 \mathrm{mg} / \mathrm{l}$ calcium disodium EDTA was degassed under vacuum while stirring. A flow rate of $0.6 \mathrm{ml} / \mathrm{min}$ was used. Volumes of $20 \mu \mathrm{l}$ were injected for assay. Calibration curves were constructed for taurine, betaine and sorbitol,

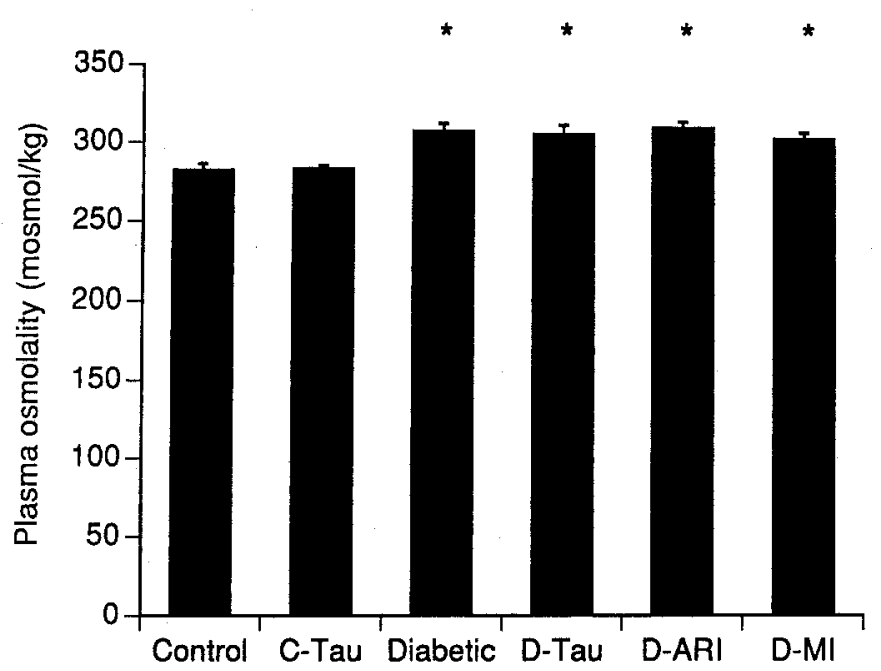

Fig. 1. The effect of diabetes, dietary osmolyte supplementation and the aldose reductase inhibitor (ARI) sorbinil on plasma osmolality measured by freezing point depression in non-diabetic control animals (control), non-diabetic control animals fed a supplemental $5 \%$ taurine diet (C-Tau), diabetic animals (diabetic), diabetic animals given the ARI sorbinil (D-ARI), diabetic animals fed a $1 \%$ myo-inositol diet (D-MI), diabetic animals fed a $5 \%$ taurine diet (D-Tau). Plasma osmolality was measured after 21 days and the data is shown as mean values with SEM bars. ${ }^{*} p<0.01$ vs control and C-Tau over a range of concentrations: each solute demonstrated linearity of response, with a recovery of greater than $95 \%$.

Plasma osmolality was measured at killing for all animals by measuring freezing point depression with an Osmette model 2007 osmometer (Precision Systems Inc, Natick, Mass., USA). The units were expressed as mosmol $/ \mathrm{kg}$.

All reagents were obtained from Sigma (St.Louis. Mo., USA) and were of the highest purity available.

\section{Statistical analysis}

Data are expressed as mean \pm SEM. Differences among experimental groups were detected by ANOVA, and the significance of differences between these groups assessed by the Student-NewmanKeuls multiple range test. As the variances for most of the variables were found to differ significantly, a logarithmic transformation was performed which corrected the unequal variances. All analyses were then performed on the transformed data. Significance was defined at the 0.05 level.

\section{Results}

\section{Effects of STZ-D and dietary taurine and MI supplementation}

Table 1 shows the baseline and day 21 body weights and plasma glucose in the different experimental groups. Baseline body weights were similar in all the experimental groups. All animals rendered diabetic achieved plasma glucose values in excess of $16.7 \mathrm{mmol} / 1$ on both day 2 and at the end of the study on day 21. Attained body weight and non-fasting plasma glucose levels at day 21 in STZ-D rats were $21-28 \%$ lower and 3- to 4-fold higher, respectively than of age-matched non-diabetic controls. Dietary taurine or MI supplementation did not alter the body weight or the plasma glucose values of either the diabetic or control animals.

\section{The effects of diabetes and taurine feeding on NCV}

The STZ-D animals showed a $23 \%(p<0.01)$ decrease in NCV after 21 days of diabetes compared to the nondiabetic control animals (Table 2). Dietary taurine supplementation for 21 days to the non-diabetic animals reduced NCV by $12 \%$ compared to the non-diabetic control animals, but after logarithmic transformation this failed to achieve statistical significance, but was not however significantly different from diabetic control animals. Restoring nerve taurine levels in the STZ-D animals by dietary taurine supplementation did not effect NCV which did not differ significantly from the untreated diabetic control animals.

\section{The effect of ARI and MI supplementation on NCV}

Nerve conduction velocity was increased by $17.1 \%$ ( $p$ $<0.05$ ) in the STZ-D animals given an ARI but still remained below the non-diabetic control animals (Table 2). The STZ-D animals treated with dietary MI supplementation also increased NCV by $14.2 \%(p<0.05)$ as has been previously reported $[21,23]$. 


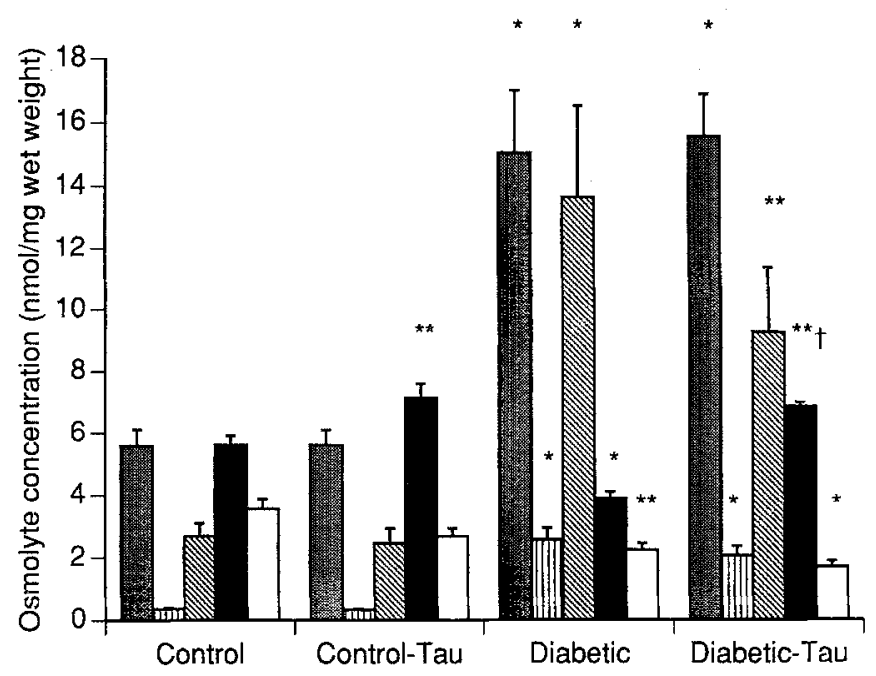

Fig. 2. The effect of $5 \%$ dietary taurine supplementation on nerve osmolyte levels in non-diabetic control animals (control), nondiabetic animals given taurine diet (control-Tau), diabetic animals (diabetic) and diabetic animals given taurine diet (diabetic-Tau). After 21 days of experimental conditions the animals were killed and the sciatic nerves were removed for measurement of nerve taurine (by HPLC) and myo-inositol $\square$, glucose 圈, sorbitol II , and fructose by gas chromatography (see Materials and methods). Data are shown as mean values with SEM bars. ${ }^{*} p<0.01$, ${ }^{* *} p$ $<0.05$ vs control; $\dagger p<0.01$ vs diabetic

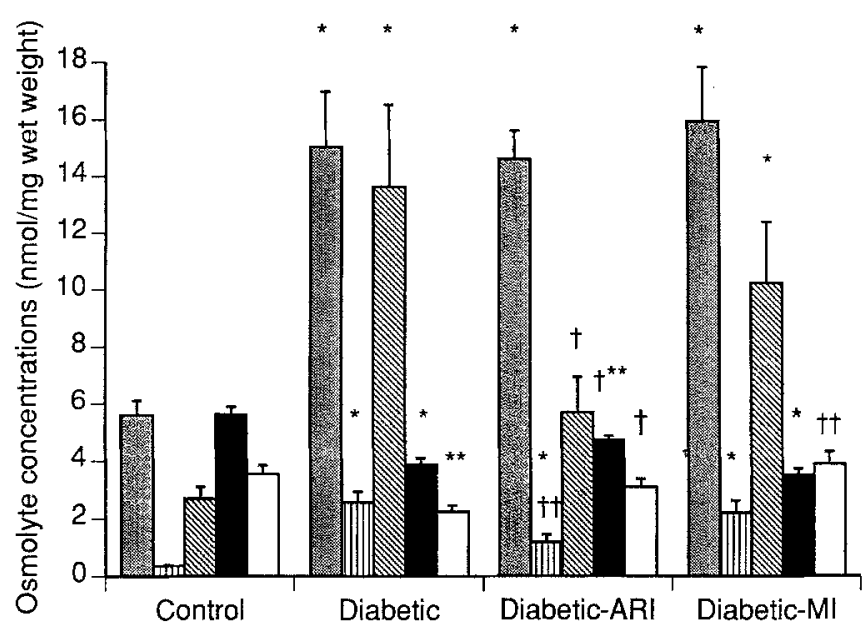

Fig. 3. The effect of 21 days of $1 \%$ dietary myo-inositol (MI) supplementation and the aldose reductase inhibitor (ARI) sorbinil on nerve osmolyte levels in non-diabetic control animals (control), diabetic animals (diabetic), diabetic animals given a $1 \%$ myo-inositol diet (diabetic-MI) and diabetic animals given sorbinil (diabeticARI). Data are shown as mean values with SEM bars. Taurine $\boldsymbol{a}$, myo-inositol $\square$, glucose , sorbitol $\mathrm{m}$, fructose $* p<0.01$, $* * p<0.05$ vs control; $\dagger p<0.05$, $\dagger \dagger p<0.01$ vs diabetic

\section{Change in plasma osmolality}

The plasma osmolality of the different experimental groups is shown in Figure 1. The plasma osmolality of the non-diabetic control animals was $282 \pm 4 \mathrm{mosmol} / \mathrm{kg}$ which was not significantly different from the nondiabetic animals given the taurine supplemented diet $(283 \pm 2 \mathrm{mosmol} / \mathrm{kg})$. All STZ-D animals showed an in- crease in plasma osmolality after 21 days of diabetes, the increase ranging from $7 \%(302 \pm 4 \mathrm{mosmol} / \mathrm{kg}, p<0.01)$ in the STZ-D group given dietary MI supplementation to $10 \%(309 \pm 4 \mathrm{mosmol} / \mathrm{kg}, p<0.01)$ in the STZ-D animals given an ARI. No significant differences were detected however between the STZ-D groups.

\section{Effect of diabetes on nerve glucose}

Neither taurine nor MI feeding nor the administration of sorbinil was found to influence nerve glucose levels as all groups of STZ-D animals achieved similar nerve glucose levels which were 2.6-2.9-fold $(p<0.01)$ above basal nondiabetic animals. No significant differences in mean nerve glucose levels were found between the STZ-D groups (Figs. 2 and 3).

\section{Effect of diabetes and taurine supplementation on nerve osmolytes}

Taurine was clearly identified by HPLC as being present in larger quantities than MI in all nerve samples assayed. STZ-D animals showed a $31 \%$ decrease in taurine ( $p$ $<0.01)$ and $37 \%$ decrease in MI levels $(p<0.05)$ after 21 days of diabetes, which coincided with accumulation of sorbitol (Fig. 2). Taurine supplementation of the diet increased nerve taurine levels by $27 \%$ in non-diabetic animals and by $78 \%$ in STZ-D animals, the diabetic animals now having taurine levels $22 \%(p<0.05)$ greater than nondiabetic control animals. Taurine feeding of non-diabetic animals resulted in a $25 \%$ decrease in nerve MI levels, although after logarithmic transformation, this decrease failed to achieve statistical significance. Basal nerve sorbitol levels were similar in both the non-diabetic control and taurine-fed control animals and were increased 7.1-fold in STZ-D animals and 5.7-fold in taurine fed STZ-D animals. Fructose levels were found to increase by 5.1 -fold in the untreated STZ-D animals and by 3.5-fold in the taurine-fed STZ-D animals compared to the non-diabetic control group. Sorbitol decreased by $8 \%$ and $20 \%$ and fructose decreased by $8 \%$ and $32 \%$ in the taurine-fed non-diabetic and STZ-D animals, respectively. These decreases however did not reach statistical significance.

\section{Effect of sorbinil and MI feeding on nerve osmolytes}

The administration of sorbinil to STZ-D animals resulted in a $54 \%(p<0.01)$ and $58 \%(p<0.05)$ decrease in nerve sorbitol and fructose, respectively, although neither level was restored to normal non-diabetic values (Fig.3). Sorbinil increased nerve taurine levels $22 \%(p<0.05)$ over untreated STZ-D animals, levels being restored to $84 \%$ of the non-diabetic levels. MI levels were found to be restored to $87 \%$ of non-diabetic levels, an increase of $38 \%$ $(p<0.05)$ in the sorbinil treated vs the STZ-D animals. MI feeding of the STZ-D animals restored nerve MI levels to non-diabetic levels and resulted in a 1.7-fold $(p<0.01)$ increase in nerve MI over the standard STZ-D animals. MI 
feeding of STZ-D animals was associated with a $9 \%$ decrease in nerve taurine levels, a $14 \%$ decrease in nerve sorbitol levels, and $25 \%$ decrease in nerve fructose levels, compared to untreated STZ-D animals, which did not reach significance.

\section{Discussion}

These results show that taurine depletion occurs in the peripheral nerve in experimental diabetes as sorbitol accumulates. Furthermore, prevention of sorbitol accumulation by the ARI sorbinil restores nerve taurine levels towards normal. MI has also previously been shown to be depleted in a similar fashion in experimental and human diabetes $[23,26]$ and this was confirmed in the present study. Taurine and MI appear to have reciprocal relationships to each other in the nerve: taurine feeding in diabetes further compounds the MI depletion. Taurine depletion in the nerve does not appear to be responsible for the decrease in NCV seen in acute experimental diabetes since restoration of taurine levels to non-diabetic levels by dietary supplementation had no effect on NCV. This contrasted with MI feeding which significantly improved NCV. Furthermore, taurine dietary supplementation in the non-diabetic state tended to deplete nerve MI levels which was accompanied by a deterioration in NCV. MI supplementation led to a slight though not significant reduction in nerve taurine levels. These data are consistent with the hypothesis that sorbitol, taurine and MI act as interdependent osmolytes within the peripheral nerve. The functional consequences of taurine depletion remain to be established.

It is now thought that the main function of aldose reductase (AR2) is osmoregulation, a process by which a cell maintains its volume and internal milieu in the face of changes in external osmolarity [27]. The peripheral nerve has been shown to contain abundant AR2, both in the Schwann cell and in the endoneurial vasculature [28], although its localization in the latter has been disputed [29]. Sorbitol, which is generated by AR 2 in the presence of excessive glucose, is poorly diffusible across the cell membrane and has been shown to accumulate in diabetic nerve $[23,30]$. In nerve, sorbitol is further metabolized to fructose, which although like glucose is present in higher quantities than sorbitol, may not contribute as significantly to the osmolyte fluxes due to its higher membrane permeability. Elucidation of its contribution to nerve osmoregulation awaits the development of selective sorbitol dehydrogenase inhibitors. Accumulation of sorbitol may therefore result in an osmotically-induced reciprocal depletion of taurine and MI. AR2 activity is induced by hyperosmotic stimuli via an induction of the AR2 gene [31]. This is important in the kidney, where cells adapted to hyperosmolality demonstrate high basal levels of AR2 protein and respond to changes in external osmolality by altering their intracellular concentration of sorbitol [32]. Whether the presence of physiological concentrations of glucose may alter the expression of the AR2 gene is less clear. High levels of AR2 activity have been associated with the development of chronic diabetes complications [33-36]. Studies in human retinal pigment epithelial (RPE) cells have shown differing basal expression and activities of AR2 and thus variable sorbitol accumulation in response to $20 \mathrm{mmol} / \mathrm{l}$ glucose [37]. In RPE cells, increases in osmolality of the magnitude observed in this study in the diabetic animals are not sufficient to induce the AR2 gene [37]. This may imply that individual variation in basal activity or expression of AR2 will determine sorbitol accumulation and secondary compensatory depletion of taurine and MI.

Sorbitol and MI are polyols which are members of one class of non-perturbing organic osmolytes, levels of which are adjusted in response to external osmolality, thereby keeping perturbing salts, such as $\mathrm{NaCl}$ and $\mathrm{KCl}$, levels constant which in excess would inhibit many metabolic processes [3]. Other classes of organic osmolytes include free amino acids, for example taurine and the methylamines, betaine and glycerophosphorylcholine (GPC) [3, $31,32,38$ ]. Levels of these osmolytes are interdependent and reciprocally deplete or accumulate in response to osmotic challenge [3]. We were unable to detect either betaine or GPC in the peripheral nerve, thus implying their greater importance in the kidney. High intracellular concentrations of taurine have been found in tissues which have a limited capacity for taurine biosynthesis [39], which implies that taurine is taken up against its concentration gradient. Like MI, taurine is accumulated by a sodiumdependent co-transporter [40]. This co-transporter has a higher affinity for beta amino acids than alpha amino acids [40] and requires chloride [40-42].

Taurine is found in very high concentrations in the brain where it is localized in both glial and neuronal fractions [43]. A previous report has documented its presence within peripheral nerve [44]. In the nervous system it has been suggested that taurine acts as a neuromodulator or inhibitory neurotransmitter $[12,13]$ and can hyperpolarize hippocampal pyramidal cells $[45,46]$. It is thought that taurine induces membrane hyperpolarization by increasing inward chloride ionic conductance $[45,47]$ and it has been implicated as a modulator of neuronal hyperexcitability, via both its hyperpolarizing effect, and by inhibition of calcium/calmodulin-dependent protein kinases [48]. This calcium-dependent protein kinase is widely distributed in neuronal tissue and is believed to contribute to the regulation of neurotransmitter release and ion conductance $[49,50]$. Increased oxidative damage has been proposed in the pathogenesis of diabetic complications [51], a process which may be exacerbated by taurine depletion as it is thought to act as an anti-oxidant $[5,11]$. High levels of taurine are found in fetal nerve tissue and progressively decline with increasing age [52] implicating its importance in neuronal growth and development. Taurine has neurotrophic actions [13] and may potentially promote neuronal regeneration, which is depressed in diabetes $[4,18,53]$. Accelerated diabetes-induced nerve taurine depletion may thus contribute to the impaired regenerative capacity of diabetic peripheral nerve.

Many of the effects of taurine may result from the regulation of intracellular calcium levels [16]. Deficiency of taurine may result in increased free calcium which may further aggravate neuronal hyperexcitability $[16,17]$. Potentially this calcium-induced hyperexcitability may 
occur acutely at either the neuronal cell body, precipitated by membrane instability [19] or impaired neurotransmitter release at sensory nerve terminals. The pain-modulating role of taurine in both acute and chronic painful neuropathy could also involve interaction with the endogenous opiate system as rats made tolerant to morphine exhibit altered distribution of taurine in the spinal cord [14]. Administration of substance $P$ to the dorsal spinal cord of rats increases the extracellular fluid taurine concentration, which serves to block some of the nociceptive stimuli induced by its administration [12].

Compensatory nerve osmolyte depletion in response to overproduction of sorbitol may be an example of osmoregulation which has gone awry. Depletion of taurine and MI may maintain intracellular osmotic balance at the expense of deteriorations of both nerve function and structure. Although dietary MI supplementation corrected nerve MI depletion and improved NCV, an effect which was independent of nerve glucose, sorbitol and fructose, this occurred at the expense of further taurine depletion. Conversely, taurine feeding of the non-diabetic animal tended to deplete MI and slow NCV, although a direct effect of taurine accumulation in the nerve cannot be excluded. In human and animal studies, ARI treatment, which prevents sorbitol synthesis and accumulation and secondary MI depletion, results in improvement of NCV and axonal transport [4]. The postulated mechanisms by which MI depletion results in impaired nerve function involves decreased sodium/potassium-ATPase activity which is important in maintaining the sodium gradient that drives both MI, and perhaps, taurine uptake in nerve. Defects in sodium/potassium-ATPase activity in the nerve result in axonal sodium accumulation, reduced resting membrane potential and subsequent impaired nerve function $[2,4,19]$. The relationships of taurine, MI and sorbitol may be critical in determining sodium/potassium-ATPase activity, intracellular $\mathrm{Ca}^{++}$and neuronal $\mathrm{Na}^{+}$, accumulation of the latter two precipitating neuronal hyperexcitability and reduced NCV, respectively. Future studies will need to directly address the function of taurine within the nerve, specifically by assessing whether repletion of taurine can stimulate nerve repilir and regeneration and/or reduce the early diabetes-induced nerve hyperexcitability.

Acknowledgements. The authors wish to express their gratitude to Ms L. Beyer for her expert technical assistance in measuring nerve osmolyte levels by gas chromatography and to Dr. T. Hohman of Wyeth Ayerst Laboratories (Princetown, NJ, USA) for his advice on aldonitrile derivatization and capillary gas chromatography methodology. We would also like to thank Dr. M. Brown of the Biostatistics Division of Michigan Diabetes Research and Training Center (MDRTC) for his advice on statistical analysis. This research was supported by USPHS R01-DK38304 and USPHS R01-DK43884 and the MDRTC (P6-DK20572).

\section{References}

1. Greene DA, Brown MJ (1987) Diabetic polyneuropathy. Sem Neurol 7: 18-29

2. Greene DA, Lattimer SA, Sima AAF (1988) Pathogenesis and prevention of diabetic neuropathy. Diabet Metabol Rev 4: 201 221
3. Burg MB, Kador PF (1988) Sorbitol, osmoregulation, and the complications of diabetes. J Clin Invest 81: 635-640

4. Greene DA, Lattimer SA, Sima AAF (1987) Sorbitol, phosphoinositides and sodium-potassium-ATPase in the pathogenesis of diabetic complications. N Engl J Med 316: 599-606

5. Malone JI, Lowitt S, Cook WR (1990) Non-osmotic diabetic cataracts. Ped Res 27:293-296

6. Shain W, Martin DL (1990) Uptake and release of taurine- an overview. Prog Clin Biol Res 351: 243-252

7. Wade JV, Olson JP, Samson FE, Nelson SR, Pazdernik TL (1988) A possible role for taurine in osmoregulation within the brain. $J$ Neurochem 51: 740-745

8. Uchida S, Nakanishi T, Moo Kwon H, Preston AS, Handler JS (1991) Taurine behaves as an osmolyte in Madin-Darby Canine cells. J Clin Invest 88: 656-662

9. Nakanishi T, Yamada T, Iida T, Uyama O, Sugita M (1990) Amino acids also accumulated in the renal rat medulla during antidiuresis. Proc XIth Int Congr Nephrol. Springer, Berlin Heidelberg New York 503 A (Abstract)

10. Jacobsen JG, Smith LH (1968) Biochemistry and physiology of taurine and taurine derivatives. Physiol Rev 48: 424-511

11. Pasantes-Morales H, Cruz C (1985) Taurine and hypotaurine inhibit light-induced lipid peroxidation and protect rod outer segment structure. Brain Res 330: 154-157

12. Davidson AN, Kaczmarek LN (1971) Taurine-a possible neurotransmitter? Nature 234: 107-108

13. Oja SS, Kontro P (1990) Neuromodulatory and trophic actions of taurine. Prog Clin Biol Res 351:69-76

14. Kuriyama K, Yoneda Y (1978) Morphine induced alterations of gamma-aminobutyric acid and taurine contents and the L-glutamate decarboxylase activity in the rat spinal cord and thalamus: possible correlation with the analgesic action of morphine. Brain Res 148: 163-179

15. Smullin DH, Skilling SR, Larson AA (1990) A possible role for taurine in analgesia. Prog Clin Biol Res 351: 129-132

16. Huxtable RJ (1987) From heart to hypothesis: a mechanism for the calcium modulatory effects actions of taurine. In: Huxtable RJ, Franconi F, Giotti A (eds) The biology of taurine: methods and mechanisms. Plenum Press, New York, pp 371-388

17. van Gelder NM (1990) Neuronal discharge hypersynchronicity and the intracranial water balance in relation to glutamic acid and taurine redistribution: migraine and epilepsy. Prog Clin Biol Res 351: $1-20$

18. Sima AAF, Prashar A, Zhang W-X, Chakrabarti S, Greene DA (1990) Preventive effect of long term aldose reductase inhibition (Ponalrestat) on nerve conduction and sural nerve structure in the spontaneously diabetic BB-rat. J Clin Invest 85: $1410-1420$

19. Buchiel KJ, Russell LC, Lee RP, Sima AAR (1985) Spontaneous nerve activity of primary afferent neurons in diabetic $B B / W$ istar rats. Diabetes 34: 1210-1213

20. Sima AAF, Brismar T (1985) Reversible diabetic nerve dysfunction. Structural correlates to electrophysiological abnormalities. Ann Neurol 18: 21-29

21. Greene DA, DeJesus PV, Winegrad AL (1975) Effects of insulin and dietary myo-inositol on impaired peripheral motor nerve conduction velocity in acute streptozotocin diabetes. J Clin Invest 55:1326-1336

22. Sima AAF, Hay K (1981) Functional aspects and pathogenetic considerations of the neuropathy in the spontaneously diabetic BB-Wistar rat. Neuropathol Appl Neurobiol 7:341-350

23. Greene DA, Lattimer SA (1983) Impaired rat sciatic nerve sodium-potassium adenosine triphosphatase in acute streptozocin diabetes and its correction by dietary myo-inositol supplementation. J Clin Invest 72: 1058-1063

24. Guerrant GO, Moss CW (1984) Determination of monosaccarides as aldonitrile, o-methyloxime, alditol and cyclitol acetate derivatives by gas chromatography. Anal Chem 56: 633-638

25. Wolff SD, Yancey PH, Stanton TS, Balaban RS (1989) A simple HPLC method for quantitating major organic solutes of renal medulla. Am J Physiol 256: F954-F956 
26. Mayhew JA, Gillon KRW, Hawthorne JN (1983) Free and lipid inositol, sorbitol and sugars in sciatic nerve obtained post-mortem from diabetic patients and control subjects. Diabetologia 24: $13-15$

27. Bedford JJ, Bagnasco SM, Kador PF, Harris HW, Burg MB (1987) Characterization and purification of mammalian osmoregulatory protein, aldose reductase, induced in renal medullary cells by high extracellular $\mathrm{NaCl}$. J Biol Chem 262: 14255-14259

28. Chakrabarti S, Sima AAF, Nakajima T, Yagihashi S, Greene DA (1987) Aldose reductase in the BB rat: isolation, immunological identification and localization in the retina and peripheral nerve. Diabetologia 30: 244-251

29. Powell HC, Garrett RS, Kador PF, Mizisin AP (1991) Fine-structural localization of aldose reductase and ouabain-sensitive, $\mathrm{K}^{+}$ dependent p-nitro-phenylphosphatase in rat peripheral nerve. Acta Neuropathol 81: 529-539

30. Gabbay KH (1973) The sorbitol pathway and the complications of diabetes. N Engl J Med 288: 831-836

31. Bagnasco S, Uchida S, Balaban R, Kador P, Burg M (1987) Induction of aldose reductase and sorbitol in renal inner medullary cells by elevated intracellular NaCl. Proc Natl Acad Sci USA 84: $1718-1720$

32. Bagnasco S, Murphy H, Bedford J, Burg M (1988) Osmoregulation by slow changes in aldose reductase and rapid changes in sorbitol flux. Am J Physiol 254: C788-C792

33. Vinores SA, Campochiaro PA, Williams EH, May EE, Green R, Sorenson RL (1988) Aldose reductase expression in human diabetic retina and retinal pigment epithelium. Diabetes 37 : 1658-1664

34. Dent MT, Tebbs SE, Gonzales AM, Ward JD, Wilson RM (1991) Neutrophil aldose reductase activity and its association with established diabetic microvascular complications. Diabetic Med 8: 439-442

35. Ghahary A, Luo J, Gong Y, Chakrabarti S, Sima AAF, Murphy LJ (1989) Increased renal aldose reductase activity, immunoreactivity and mRNA in streptozotocin-induced diabetic rats. Diabetes 38: 1067-1071

36. Ghahary A, Chakrabarti S, Murphy LJ, Sima AAF (1991) Effect of insulin and statil on aldose reductase expression in diabetic rats. Diabetes 40: 1391-1396

37. Henry DN, Stevens MJ, Killen PD, Greene DA (1992) Aldose reductase (AR2) gene expression in cultured human retinal pigment epithelial cells (RPE). Diabetologia 35 [Suppl 1]: A 139 (Abstract)

38. Bagnasco S, Balaban R, Fales H, Yang Y-M, Burg MB (1986) Predominant osmotically active organic solutes in rat and rabbit medullas. J Biol Chem 261: 5872-5877

39. Huxtable RJ, Lippincott SE (1982) Relative contribution of diet and biosynthesis to the taurine content of the adult rat. Drug Nutr Interact 1: 153-168
40. Chesney RW (1985) Taurine: its biological role and clinical implications. Adv Pediatr 32: 1-42

41. Karl PI, Fisher SE (1990) Taurine transport by microvillous membrane vesicles and the perfused cotyledon of the human placenta. Am J Physiol 258: C443-C451.

42. Wolf NA, Kinne R (1988) Taurine transport by rabbit brush-border membranes: coupling to sodium, chloride, and membrane potential. J Membr Biol 102: 131-139

43. Sellstrom A, Sjoberg L-B, Hamberger A (1975) Neuronal and glial systems for gamma aminobutyric acid metabolism. J Neurochem 25: 393-398

44. Malone JI, Harvey R, Benford S, Mandlow S (1985) Taurine deficiency in the sciatic nerve and lens of the STZ-D rat. Diabetes 34 [Suppl]: P 102 (Abstract)

45. Lerma J, Herranz AS, Herreras O, Munoz D, Solis JM, del Rio RM, Delgado JMR (1985) Gamma-aminobutyric acid increases the in vivo extracellular taurine in the rat hippocampus. J Neurochem 44: 983-986

46. Taber KH, Thalman RH (1983) Response of rat hippocampal neurons to taurine. Soc Neurosci 9: 414 (Abstract)

47. Hodgkin AL, Horowicz P (1960) The effect of sudden changes in ionic concentrations on the membrane potential of single muscle fiber. J Physiol (Lond) 153: 370-385

48. Lombardi JB (1985) Effects of taurine on calcium ion uptake and protein phosphorylation in rat retinal membrane preparations. $\mathrm{J}$ Neurochem 45: 268-275

49. Cheung WY (1980) Calmodulin plays a pivotal role in cellular regulation. Science 207: 17-19

50. Nestler EJ, Greengard P (1983) Protein phosphorylation in the brain. Nature 305: 583-588

51. Low PA, Nickander KK (1991) Oxygen free radical effects in sciatic nerve in experimental diabetes. Diabetes 40: 873-877

52. Sturman JA (1988) Taurine in development. J Nutr 118: 1169 1170

53. Sima AAF, Bril V, Nathaniel V, et al. (1988) Regeneration and repair of myelinated fibers in sural-nerve biopsy specimens from patients with diabetic neuropathy treated with sorbinil. N Engl J Med 319: 548-555

Received: 8 December 1992

and in revised form: 8 March 1993

Dr. M.J.Stevens

Room 5570, MSRB-II

Box 0678

1150 W. Medical Center Drive

University of Michigan

Ann Arbor, MI 48109

USA 